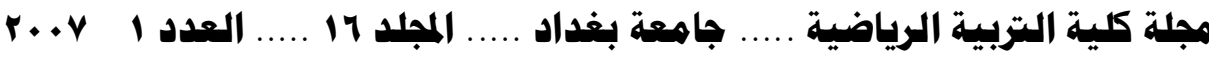

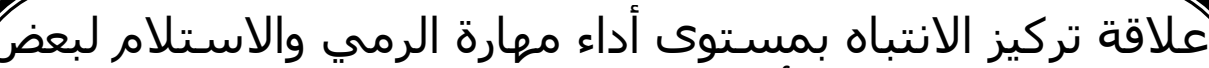

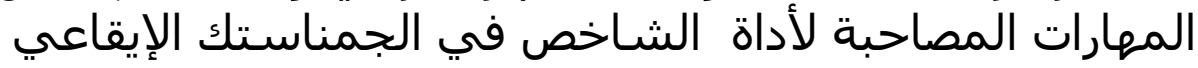

\section{بحث وصفي}

على طالبات المرحلة الأولى في كلية التربية الرياضية جامعة بغداد/الجادرية

$$
\begin{aligned}
& \text { م.م. إيمان عبد حسن } \\
& \text { م r.V }
\end{aligned}
$$

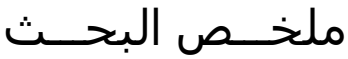

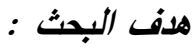

- معرفة علاقة تركيز الانتباه بمستوى اداء مهارة الرمي والاستلام للشاخص في الجمناستك الايقاعي .

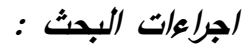

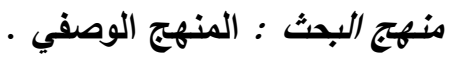
عينة البحث : طالبات المرحلة الاولى في كلية التربية الرياضية - جامعة بغداد- الجادرية وعددهن (40) طالبة . المعالجات الاحصائية : المهاتية

الوسط الحسابي ، الانحراف المعياري ، الوسيط ، معامل الالتواء ، معامل الارتباط البسيط .

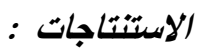

وجود علاقة ارتباط معنوية بين تركيز الانتباه ومستوى اداء مهارة الرمي والاستلام للشاخص . 


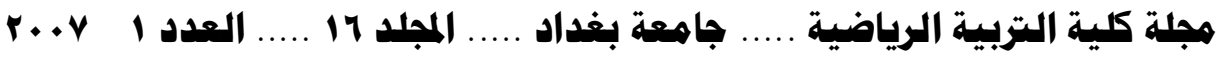

التاكيد على تطوير تركيز الانتباه من خلال الوحدات التعليمية ( اللاروس) لوجود علاقة بين هذا

$$
\text { - المراء بحوث ومستوى الرمي والاستلام. }
$$

- زيـادة معلومـات المدرسين بمظـاهر الانتبـاه ويـالاخص تركيز الانتبـاه مـن خـلال اقامـة الدورات

التدريبية لهه مهادهات

\section{ABSTRACT}

The Relation ship Between Concentration of Attention and the level of performing and receiving in same skills used with clups in rhythmic gymnastics .

The aim of the study :

- Identifying the relationship between concentration of attention and the level of performing throwing and receiving the clup in Rhythmic Gymnastics.

The procedures :

- Method of Research: The descriptive method.

- Subjects: First year female students of the college of physical Education - University Baghdad - Al - Jadria - they were (40) students.

Statistical Analysis:

Media, standard deviation, simple correlation coefficient.

Conclusion:

There is a significant relationship between concentration of attention and level of performing throwing and receiving the clup.

Recommendations:

1. Developing the concentration of attention through teaching sessions.

2. Making similar studies about other aspects of attention.

3. Increasing the teachers information concerning the aspects of attention through making special training courses.

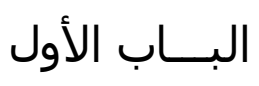

$$
\text { | - التعريف بالبحث المقدمة والهمية البحث }
$$




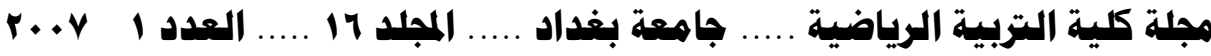

أن التطور الكبيز الذي شـهـه العـالم في الاونـة في كافة الميـادين ومنها الميدان الرياضـي يعد مؤشرا لمدى الاهتمام الكبير المبذول من قبل المختصين والباحثين في تطور العملية التعليمية والتدريبية بصورة مستمرة من اجل رفع المستوى الرياضي وتحقيق أفضل الانجازات . ويعتبر الانتباه بمظاهره المتعددة احد الجوانب النفسية التي تؤدي الى توجيه الشعور وتركيزه في شيء معين استعداد لملاحظته او اداءه او التفكير فيه وتمثل القدرة على تركيزه وحسن توجيهه اهم الثروط لتوفير النجاح (') ان لعبة الجمناستك الايقاعي من الالعاب التي تحتاج الى دقة في تركيز الانتباه وذلك لمرافقة الاداء المهاري الـى الادوات ومنها الشـاخص الذي فيسه تحتـاج اللعبـة الـى تركيز الانتباه على الاداة بين الاداء المهاري وعمل تلك الاداة .

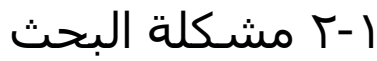
ان مهارة الرمسي والاستلام تعد مـن المهارات المهــة ومـن المتطلبـات الخاصـة في الجمناستثك الايقـاعي ، واحـدى الادوات التـي تسـتعمل فيهـا هـذه المهـارة هـي اداة الثــاخص ومـن خـلال المتابعـة

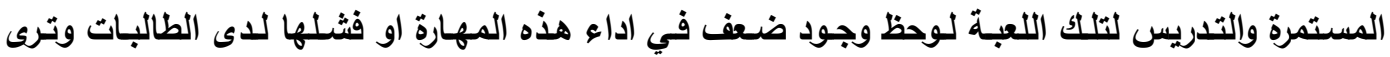
الباحثة ان احد اسباب هذا الضعف هو القصور في عملية التهيؤ والتركيز قبل اداء هذه المهارة ، لذا ارتأت الباحثة دراسة هذه المشكلة والتعرف عليها للتوصل الى الحلول المناسبة لخدمة هذه اللعبة .

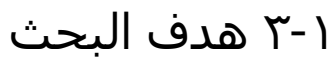

- معرفة علاقة تركيز الانتباه بمستوى اداء مهارة الرمي والاستلام للشاخص في الجمناستك الايقاعي .

$$
\text { | }
$$

- - هنـاك علاقـة ارتبـاط معنوي بـين تركيز الانتبـاه ومسـتوى أداء مهارة الرمسي والاستلام للشـاخص في

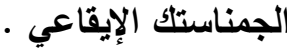
| - 1 - 1 مجالات البحث

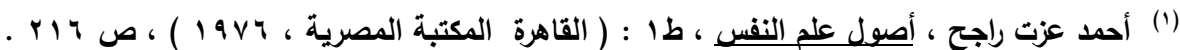
$(r+r)$ 


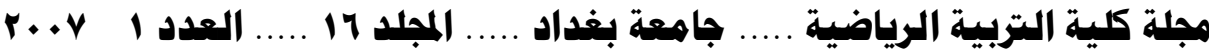

1 - - - المجال البثري :- طالبات المرحلة الأولى في كلية التربية الرياضية / الجادرية.

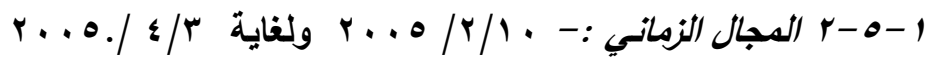

1 - - - الم المجال المكانسي :- قاعة الجمناستك الاخلية للبنات في كلية التربية الرياضية - جامعة بغداد

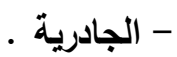

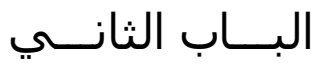

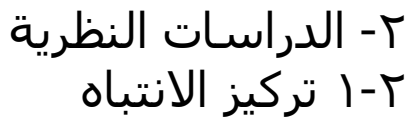

يلعب الانتباه دورا هاما في حياة الانسان لمساهمته في التعرف على البيئة وتكيفه واتصـاله بها

حيث يعد من الاسس التي تقوم عليها مختلف العمليات العقلية العليا فبدون الاتتباه لايستطيع الانسـان ان

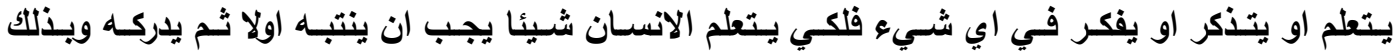
فالانتباه في المجال الرياضـي مهم جدا وان عملية الانتباه تختلف من شخص لاخر حيث يوجد شخص الخص

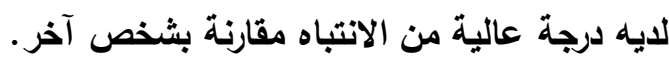

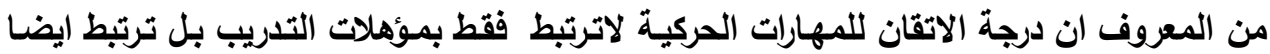

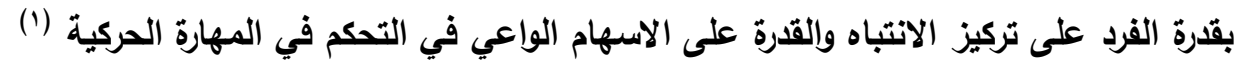

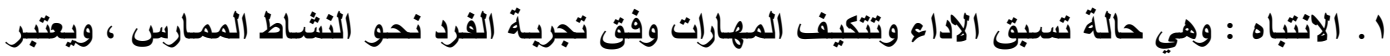

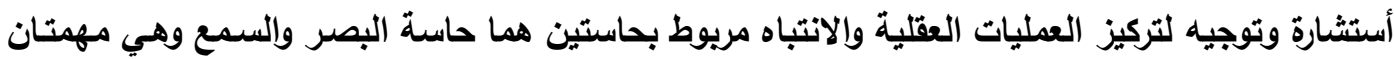
جدا في جميع الحركات الرياضية ويعتمد الانتباه على شدة المثيرة وحجمة وتكراره حيث يتطور الانتباه من من مناه خلال التكرار والتجريـة ويتأثر بشكل سلبي بحالات الاجهاد الشديدة ولان الكائن الحي لا يستطيع الانتباه عندما يكون جهاز العصبي في حالة تعب شديد ('). r. التركيز : وهو تجميع كافة الافكار والعمليات الفكرية بنقطة واحدة لخدمة العمل المهاري المراد تحقيقهـ ، وهو عملية قطع عن المحيط الخارجي لاداء أدق المهارات الحركية (؟). 


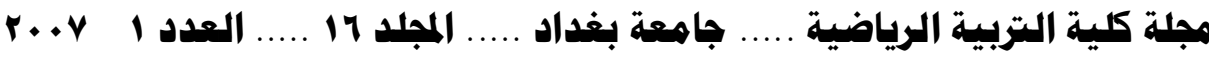

وترتبط عملية التركيز بالانتباه مباشرة حيث تعد مرحلة مكملة لها فالتركيز هنا تجميع العمليات

العقلية لفترة قصيرة ولكن الانتباه تجميع العمليات الفكرية لمدة أطول.

يعد الانتباه من الموضوعات النفسية المهـة التي لها علاقة بـالاداء الحركي حيث يلعب هذا العنصر دورا فاعلا في تحقيق مستوى اداء افضل ونخص بالذكر تركيز الانتباه الذي لـه الدور الفاعل في كثير من الالعاب ومنها الجمناستك الايقاعي الذي يرافق الاداء الحركي السى الادوات بحيث يحتاج السى

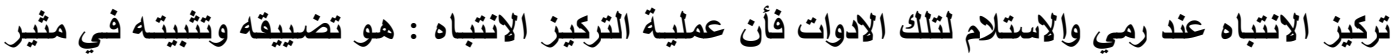
معين واستمرار الانتباه لهذا الميثر وليس معناه جمود المثير في مكان ثابت وإنما امتداد واتسـاع الانتباه ولكن في حدود تتبع الميثر المختار (").

ץ- ب العوامل المؤثرة على الانتباه

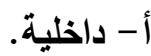

1- اختيار طريقة انتباه لكل نشاط نوع انتباه . أ- داخلي واسع - تخطيط للمعلومات. ب - خارجي واسع - تقييم للموقف. ج- داخلي - ضيق - توجيه الانتباه. ع- خارجي - ضيق - عند محاولة الاستجابة أو الاداء . r - توقيت تحويل الانتباه - سريع ، بطيء تسلم الكرة. r - الضغط العصبي.

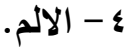
ب - عوامل خارجية. - صعوية المثيرات وإلمؤقت.

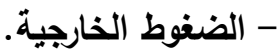
ץ - r الجمناستك الايقاعي 


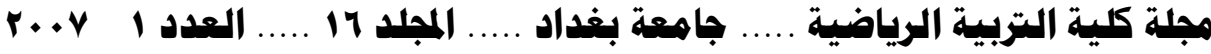

تعد رياضـة الايقـاعي بوصفهـا أحــ الانثـطة الحركيـة التـي تطـور مـن قوة الارادة والملاحظـة

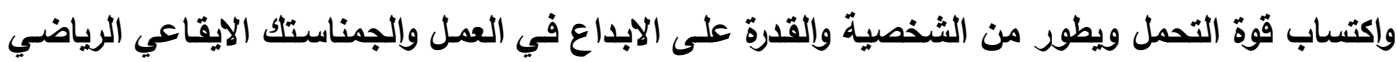
هو نشاط حركي يعمل على حركة الجسم واجزائه بوزن حركي ومصاحبة ذلك بالموسيقى ، وهذا يؤدي الى لى

أنسجام بين أجزاء واقسام الحركة حيث يمتاز هذا النشاط بالطابع الجمالي ويالتعبير الفني للحركات (1).

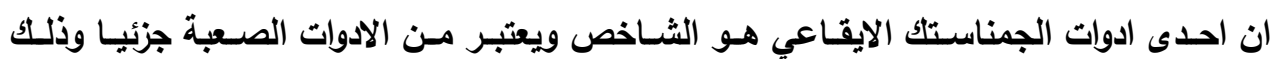
لصلابة الاداة وعدم مرونتها وينفس الوقت .

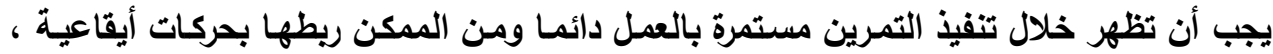

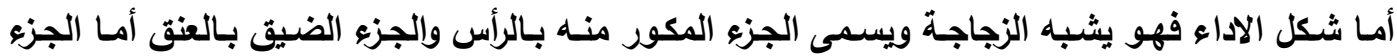

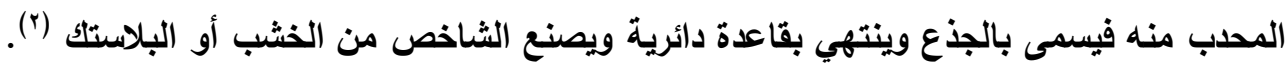
أن الرمس والاستلام عنصران يصعب تنفيذهما لذلك يتطلب براعة في التكنيك وسيطرة وتركيزا

عاليا (r)

$$
\begin{aligned}
& \text { البـــــاب الثالـــــث } \\
& \text { ץ- منهج البحث واجراءاته الميدانية } \\
& \text { r-1 منبوج البحث }
\end{aligned}
$$

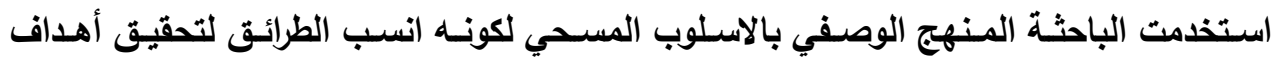

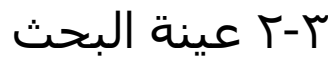
تم اختيار عينة البحث بالطريقة العمدية وتكونت من ( • ؛ ) طالبة يمثلن طالبات المرحلة الاولى من كلية التربية الرياضية / الجادرية وقامت الباحثة بأخذ بعض القياسـات الانثروبومتريـة التي تعد مهمـة جدا عند أجراء تجرية البحث وهي ( الطول والوزن والعمر ) وذلك لمعرفة مدى تجانس العينة ، لذا عمدت

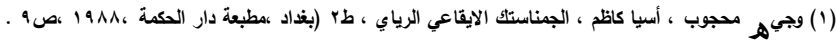

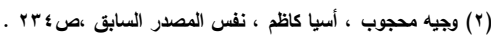

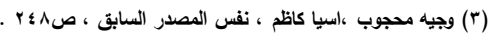




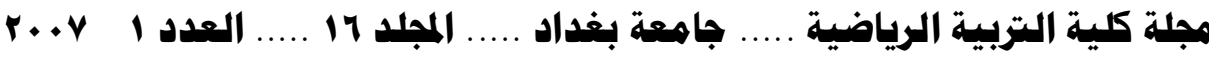

الباحثة السى استخدام (معامل الالتواء) الذي اظهر تجانس افراد الشروع بتطبيق التجربـة الرئيسية وكمـا

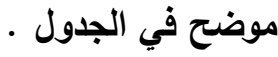

r- r ادوات البحث

من الادوات والمستلزمات الضرورية التي استخدمتها الباحثة لاتمام البحث :

- - - مأستمارة استبيان

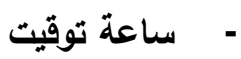

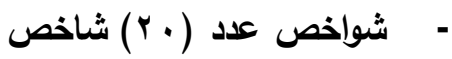

-

-

- م - الوسائل الاحصائية .

ץ- $\Sigma$ فريق العمل المساعد

شمل فريق العمل المساعد على كل من :

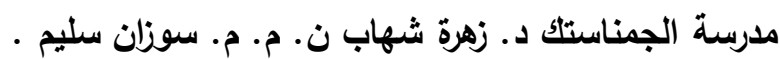

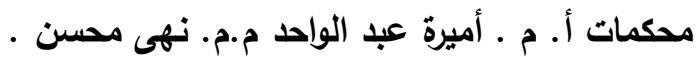

جدول (1)

المعالجة الاحصائية لمتغيرات الطول والوزن والعمر لافراد عينة البحث

\begin{tabular}{|c|c|c|c|c|c|}
\hline \multirow{2}{*}{ قيمة معامل } & \multicolumn{3}{|c|}{ المعالجة الاحصائية } & \multirow[b]{2}{*}{ المتغيرات } & \multirow{2}{*}{ ت } \\
\hline & $\varepsilon \pm$ & الوسيط & س & & \\
\hline •, & r,vo & 109 & $17 ., 17$ & الطول (بالسم) & 1 \\
\hline$\cdot, 11$ & $r, \Delta r$ & ov & $\Delta V, r$. & الوزن (بالكلغم) & r \\
\hline $1, \leqslant 0$ & $\cdot, \uparrow \wedge$ & $r \cdot, \theta$ & $r \cdot, 17$ & العمر(بالسنوات) & $r$ \\
\hline
\end{tabular}

r- 0 اختبار شبكة تركيز الانتباه 


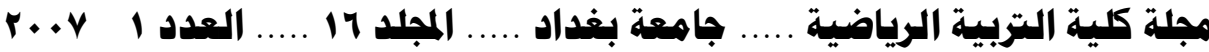

مدة الاختبار دقيقة واحدة ويطلب من اللاعب ان يضع شرطه على ( / ) على اكبر عدد ممكن

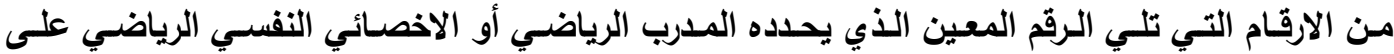

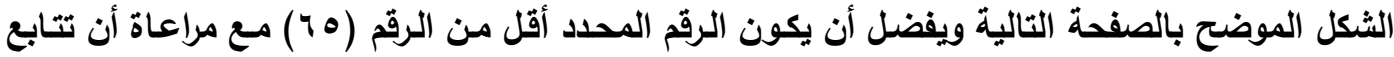
الارقام بطريقة متتالية فمثلا عند تحديد رقم البدء بالرقم (IV ) فينبفي على اللاعب أن يقوم بوضع شرطه

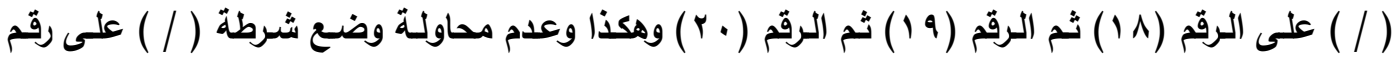

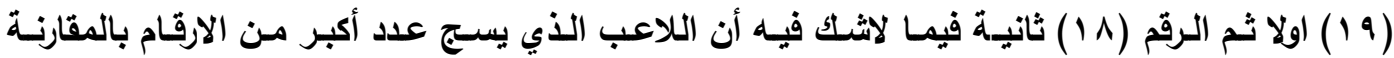
بزملائه يكون لايه تركيز أقل ويمكن أستخدام هذا الاختبار عدة مرات مـع تغيير الرقم الابتدائي اعمدة في لهي

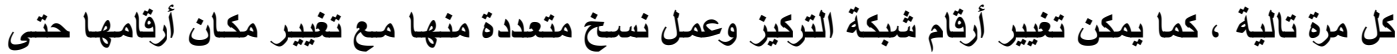
لايتعود اللاعبون على حفظ وتذكر مكان الارقام .

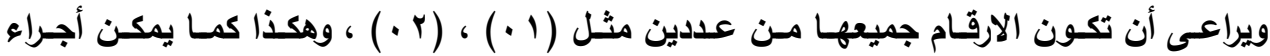

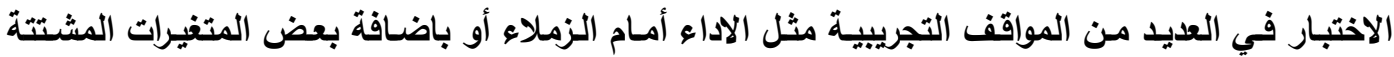
ليلانتباه .

يتم أحصاء الارقام التي قام اللاعب الرياضس بثطبها بطريقة صحيحة في غضون فترة الاقيقة المحددة لاجراء الاختبار ويتم منح درجة واحدة لكل رقم مشطوب بطريقة صحيحة ولكما أرتفعت درجات اللاعب الرياضي كلما دل ذلك على قرتهه العالية على تركيز الانتباه ( )

\begin{tabular}{|c|c|c|c|c|c|c|c|c|c|}
\hline$\Lambda \varepsilon$ & $r V$ & 01 & $\vee \wedge$ & 09 & Or & ir & 10 & 71 & $\Delta$ \\
\hline$r \wedge$ & 7. & $q r$ & . $\leq$ & $9 \mathrm{~V}$ & 9. & r & $\Delta V$ & rq & r \\
\hline$r r$ & 97 & 70 & rq & $\Lambda$. & VV & $\leqslant 9$ & 14 & 11 & $v$. \\
\hline V & $\Lambda \vee$ & $V_{1}$ & 90 & $9 \wedge$ & $\wedge 1$ & .1 & $\leqslant 7$ & $\wedge \wedge$ & .. \\
\hline$\leqslant \wedge$ & $\Lambda r$ & 19 & $\leqslant V$ & ro & $1 \mathrm{~V}$ & 1. & $\varepsilon r$ & YY & \\
\hline$\leqslant \varepsilon$ & $7 V$ & $q r$ & 11 & $\cdot v$ & $\varepsilon r$ & $V Y$ & $9 \leq$ & 79 & ד \\
\hline
\end{tabular}

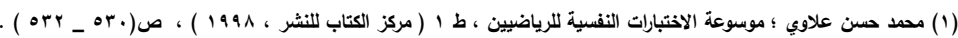




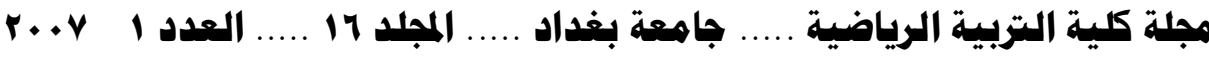

\begin{tabular}{|c|c|c|c|c|c|c|c|c|c|}
\hline or & Vq & .0 & $r r$ & $0\}$ & $V \varepsilon$ & $0 \wedge$ & $1 \varepsilon$ & 91 & $\cdot r$ \\
\hline .7 & 71 & 99 & vo & rq & 10 & \&1 & 7 & $r$. & $\varepsilon$. \\
\hline D. & .9 & $7 \leq$ & $\cdot 1$ & rᄉ & $r$. & rq & $\leq 0$ & N & $r \varepsilon$ \\
\hline .r & Vr & YI & $r r$ & 17 & $r v$ & ro & 19 & Ir & זד \\
\hline
\end{tabular}

r- 7 التجربة الاستطلاعية

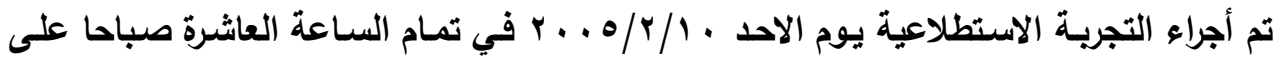

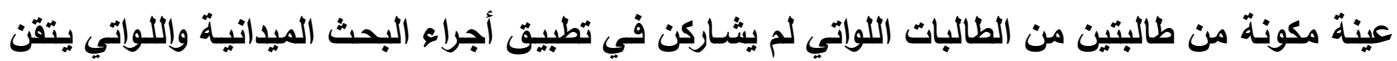

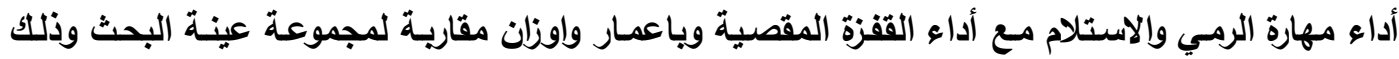

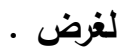

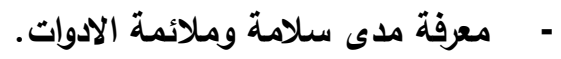
- - تلافي المعوقات التي قد تظهر خلال أداء ألاختبار.

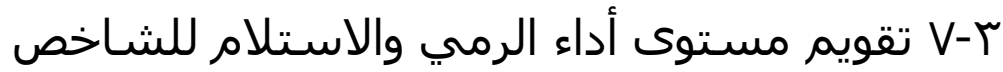
قبل البدء بعملية تنفيذ أجراءات البحث من أجل التأكل من صلاحية الاختبار لقياس مستوى أداء

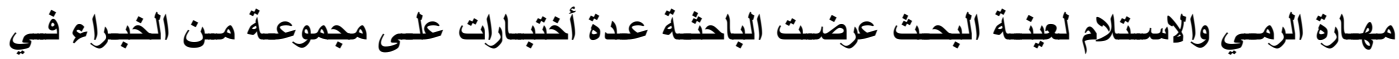
الجمناستك الايقاعي حيث تم أختيارهم للاختبار الاتي :

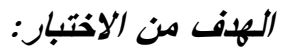
قياس مستوى أداء الرمي وألاستلام للشاخص : لإنص

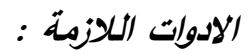

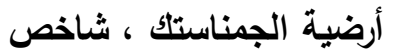
وصف الاداء : تقف المختبرة على أرضية الجمناستك وتؤدي مهارة ألرمي لثشاخص باليمين ومرة بذراع اليسار يرافق ذلك مهارة القفزة المقصية . التسجيل : التهار 


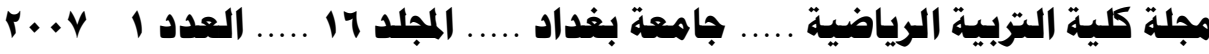

1. تمنح الطالبة (ه) درجات أذا أدت المهارة بثكل صحيح أضافة الى الرمي وألاستلام الصحيح .

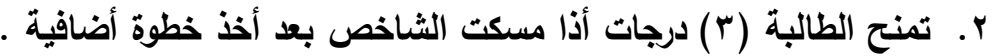
r. لا تحصل الطالبة على درجة أذا سقط الثاخص على الارض .

$$
\text { ب-1 الوسائل الإحصائية }
$$

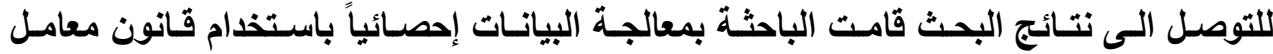

الارتباط البسيطة ( بيرسيون )(').

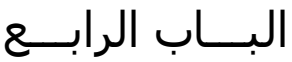

ع- عرض النتائج وتحليلها ومناقشتهبا

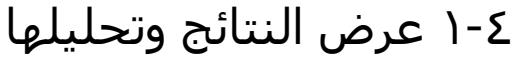

لغرض أثبات صحة الفرض المقدم في هذا البحث والمتضمن ( هناك علاقة ذات دلالة أحصائية بين تركيز الانتباه ومستوى أداء الرمي وألاستلام للشـاخص في الجمناستك الايقاعي ) تم استخراج معامل الارتباط البسيط (ر) بين تركيز الانتباه ويين مستوى أداء ألرمي والاستثلام . ثم أستخراج معامل الارتباط البسيط حيث أثـارت النتائج الى وجود أرتباط عال نسبيا بين تركيز

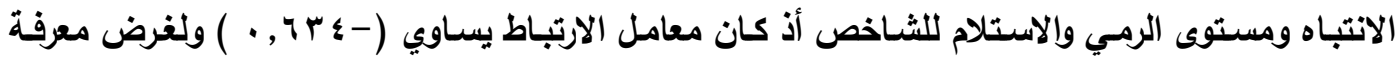

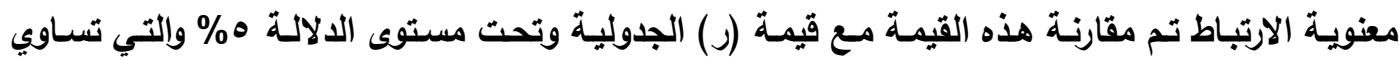

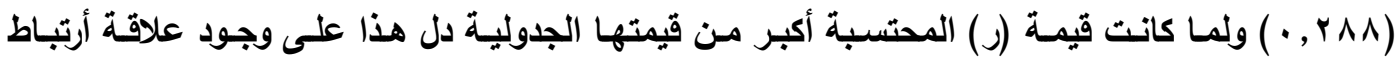
عالية (عكسية ) بين تركيز الانتباه ومستوى أداء مهارة الرمي والاستلام .

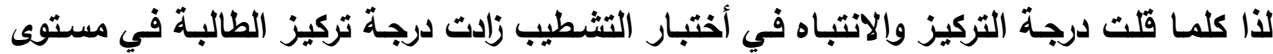

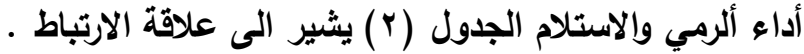

جلول (r) (r)

\begin{tabular}{|c|c|c|}
\hline قيمة (ر) المحتسبة & مستوى الرمي والاستلام & المظهر \\
\hline פ & مستوى الرمي والاستلام للشاخص & تركيز الانتباة \\
\hline
\end{tabular}

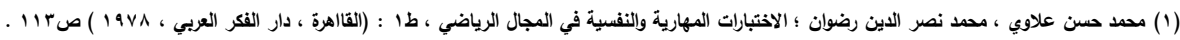




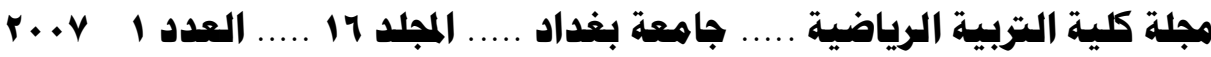

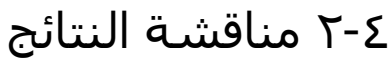

أظهرت نتائج البحث الى وجود علاثة أرتباط مغنوية عالية بين تركيز الانتباه ومستوى الرمي

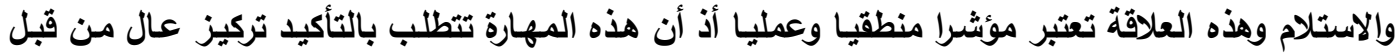

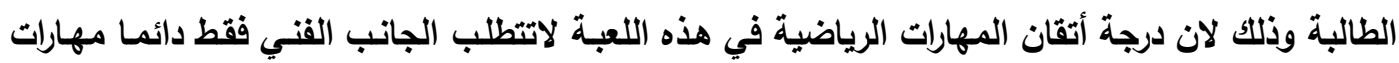

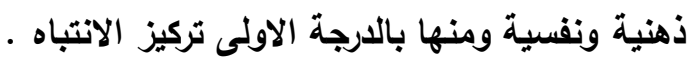
أن امتلاك عينة البحث لهذا المظهر يعتبر مؤثشرا ايجابيا لكونـه يرتبط بأهم مهارة وهي ألرمي

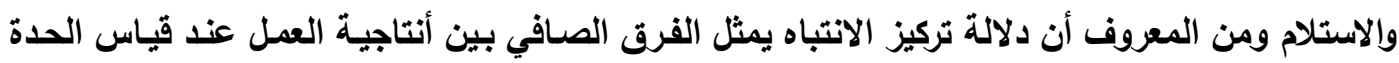

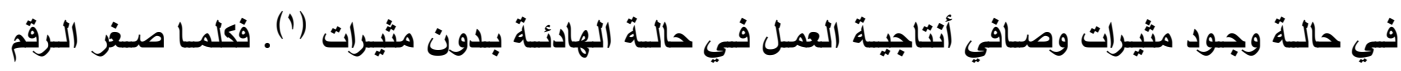
المستخرج من أختبار التثطيب دل ذلك على أرتفاع درجة تركيز الانتباه لاى الطالبة وتحسن مستوى اداء الهاء

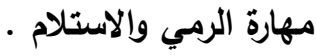




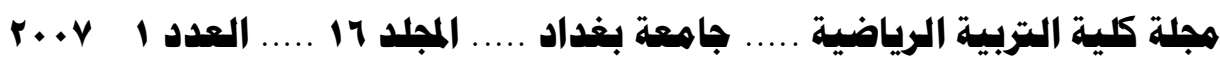

$$
\begin{aligned}
& \text { البــــاب الخامــــــــ } \\
& \text { 0- الاسـتناجات والتوصيات }
\end{aligned}
$$

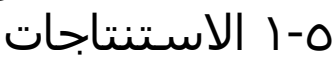

وجود علاقة أرتباط معنوية بين تركيز الانتباه ومستوى أداء مهارة ألرمي وألاستلام للشاخص .

r-0

1. التأكيد على تطوير تركيز الانتباه من خـلال الدروس ( الوحدات التعليمية ) لوجود علاقة بين

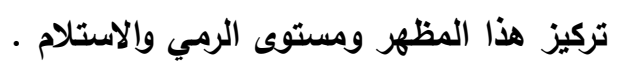

r. أجراء بحوث بدراسة المظاهر الاخرى للانتباه

r. زيـادة معلومـات المدرسـات بمظـاهر الانتبـاه ويـالاخص تركيز الانتبـاه مـن خـلال أقامـة الدورات

التدريبية لهم مهودان 


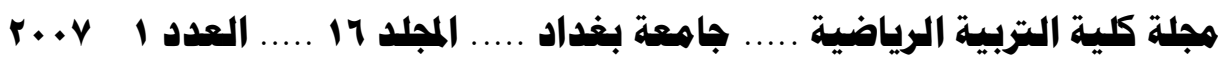

\section{المصــادر}

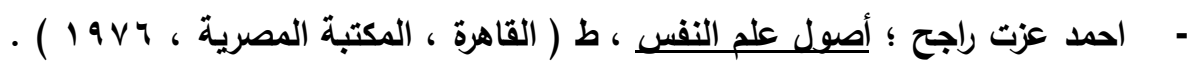

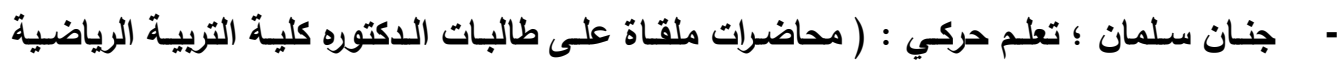

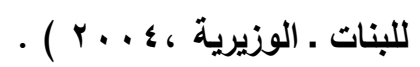

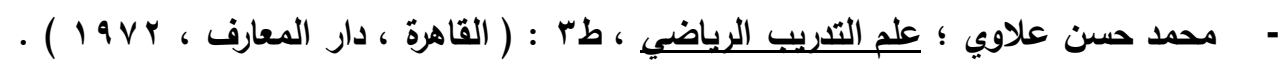

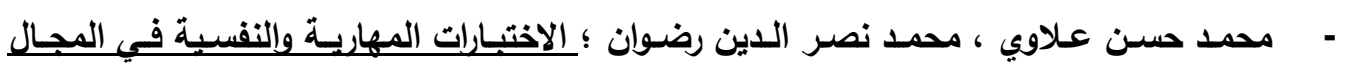

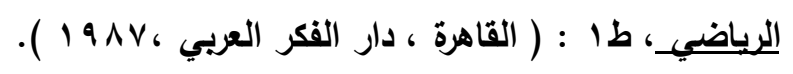

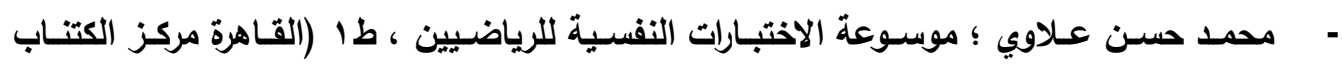

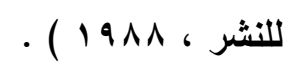
- مجلة علمية متخصصة لبحوث التربية البذنية والرياضية ؛ نظريات وتطبيقات : جامعة الحلوان

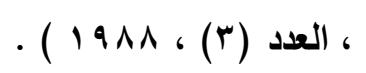

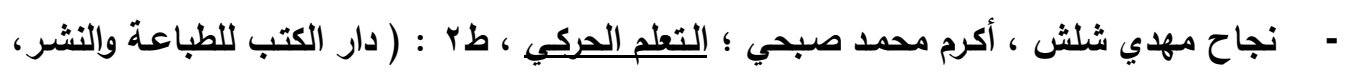

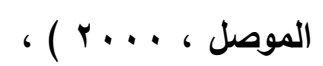

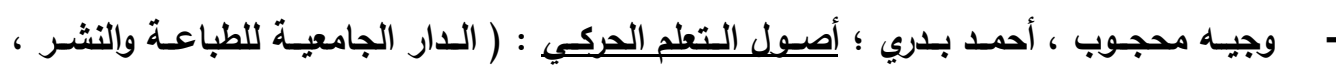

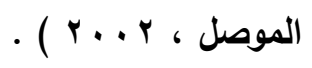

